Journal of Animal and Veterinary Advances $11(8): 1166-1172,2012$

ISSN: $1680-5593$

(C) Medwell Journals, 2012

\title{
Establishment of Two Types of Mammary Epithelial Cell Lines from Chinese Holstein Dairy Cow
}

\author{
Chunyan Lu, Runjun Yang, Boyang Liu, Zezhong Li, Binglei Shen, Shouqing Yan, \\ Yonghong Zhang, Liying Zhang and Zhihui Zhao \\ Jilin Provincial Key Laboratory of Animal Embryo Engineering, \\ College of Animal Science and Veterinary Medicine, \\ Jilin University, 5333 Xi'an Road, 130062 Changchun, Jilin Province, China
}

\begin{abstract}
Chinese Holstein dairy cow is the main dairy cow in China. With the development of Chinese milk industry, more attention is being placed on the factors that might affect milk quality, especially milk fat and milk protein content. So, the objective of this study was to establish a culture system for two types of bovine mammary epithelial cell line, high fat high protein Mammary Epithelial Cell line (MEC-HH) and low fat low protein Mammary Epithelial Cell Line (MEC-LL) in vitro and elucidate the unique characteristics of these cell lines. Mammary tissues from two lactating dairy cows whose milk were high fat high protein content and low fat low protein content were used as sources of these epithelial cell lines. The tissues were cultured in plastic dishes by the method of tissue nubbles culture. Fibroblast and epithelial cells successively grew and extended from mammary tissues after 6 days from low fat low protein cow but 10 days from high fat high protein cow and pure epithelial cells were obtained by continuous culture and digestion for 3-5 times. The epithelial cells cultured in the 10\% FBS maintained a normal growth tendency and had normal cell nucleus. The $\alpha$-s 1 casein and $\kappa$-casein expression of epithelial cells were detected by RT-PCR. The positive immunocytochemistry to cytokeratin 18 suggested the obtained cell line exhibited the specific character of epithelial cells. A TG-kit was used to detect the TG content of the two types of cells, the results showed that the cell lines kept the character of high fat and low fat cows in the 1 st and 2 nd passages. The obtained mammary epithelial cell lines had normal morphology, growth characteristics, cytogenetic and secretory characteristics. Thus, it might supply a useful tool for studying the gene function about milk fat and protein. The research provides the basis for the future study of lipometabolism mechanism in dairy cow.
\end{abstract}

Key words: Mammary epithelial, Chinese Holstein dairy cow, cell lines, fat, protein, China

\section{INTRODUCTION}

In the bovine species, milk production is well known to correlate with mammary tissue. However, most advanced techniques in optimizing milk production relied on improvements of breeding and husbandry practices (Zakizadeh et al., 2007; Gorgulu, 2011; Martignani et al., 2010). The Chinese Holstein cow is the main diary cow in China. With the fast development of the Chinese milk industry, more attention is being placed on the mechanisms or factors that might affect milk synthesis and quality, especially fat and protein (Han et al., 2011; Huang et al., 2011).

Collagenase dissociation has been used successfully during isolation and culture of bovine epithelial cells in vitro (Baumrucker et al., 1988; Huynh et al., 1991). Tissue culture is another method which was successfully used to isolate bovine mammary epithelial cells (Rapp and
Melnick, 1964; Rose et al., 2002). Mammary tissue cell or explants have been used over the years as a bioreactor model to understand its physiological function (Pantschenko et al., 2000a). Milk synthesis occurs within clusters of differentiated mammary epithelial cell and is controlled by lactogenic hormones and extracellular matrix interactions (Cifrian et al., 1994). A method for establishment of mammary epithelial cell lines from human has been described (Ceriani et al., 1979). Several MEC lines had been existed including BMEC+H (Schmid et al., 1983), MAC-T (Szyda and Komisarek, 2007), PS-BME (Jack and Mather, 1990), BME-UV (Zavizion et al., 1996) and L-1 (German and Barash, 2002), CMECs (Hu et al., 2009). However, the level of milk protein synthesis of these MEC lines is either very low or non-existent. These cell lines are not suitable for investigations of mammary gland function.

Corresponding Author: Zhihui Zhao, Jilin Provincial Key Laboratory of Animal Embryo Engineering,

College of Animal Science and Veterinary Medicine, Jilin University,

5333 Xi' an Road, 130062 Changchun, Jilin Province, China 
The study established two mammary epithelial cell lines from Chinese Holstein cows whose milk contained high fat high protein and low fat low protein with tissue culture method and the MECs were thoroughly characterized via morphology, growth curves, staining analysis of cells nucleus, RT-PCR and immunocytochemistry (Pantschenko et al., 2000b). The comparison about the two cell lines were done by detection of TG contents and the isolated MECs have been used for investigation of gene function about milk fat and protein and lipometabolism mechanism study.

\section{MATERIALS AND METHODS}

Samples selection and collection of mammary tissue: Milk fat and protein content from 11 Chinese Holstein cows which were grown in the same circumstance were analyzed by milk composition analyses machine for 9 days and monitored 2 times per day (Table 1 and 2). The mammary tissue from the No. 33 cows whose milk fat and protein content were highest (fat content was 4.30 , protein content was 3.91) and the No.16 cow whose milk fat and protein content were lowest (fat content was 2.41 , protein content was 2.80) were selected as samples were butchered in slaughter house for their mammary tissue.
Isolation of mammary tissue and culture of mammary epithelial cells: Two types of bovine mammary tissue were obtained from a high-fat high-protein and a low-fat low-protein lactating Chinese Holstein dairy cows. Fresh tissues were placed in an incubation box at $37^{\circ} \mathrm{C}$ in PBS (Tiangen, Beijing, China) solution with $5 \%(\mathrm{v} / \mathrm{v})$ penicillin and streptomycin (Tiangen) and immediately transported to the laboratory. Mammary tissues were then washed with PBS solution for several times until the solution was limpid and without milk. Tissues were then cut into about $1 \mathrm{~mm}^{3}$ nubble and washed again with PBS solution until tissue was clean. The smaller pieces of tissue were transferred onto cell culture dishes (Falcon, Franklin Lakes, NJ, USA). The basal media was prepared in advance: DMEM/F12 (GIBCO invitrogen, Carlsbad, California, USA) with $10 \%(\mathrm{v} / \mathrm{v})$ fetal bovine serum (GIBCO) (Ethier, 1986) and $1 \%(\mathrm{v} / \mathrm{v})$ penicillin and streptomycin (Tiangen, Beijing, China) and 1\% (v/v) epithelial growth factor (GIBCO) which could promote the growth of the epithelial cells. About 2-3 drops of basal media were added ensuring that the tissue was not dry. Then, the cell culture dishes with tissue were incubated at $37^{\circ} \mathrm{C}, 5 \% \mathrm{CO}_{2}$ in a $\mathrm{CO}_{2}$ incubator (Thermo, Marietta, Ohio, USA). After $6 \mathrm{~h}, 5 \mathrm{~mL}$ basal media were added to every dish ensuring that the tissues would not float and separate from the bottom of the culture dish. The basal

Table 1: Milk fat content in 11 Chinese Holstein cows (\%)

\begin{tabular}{|c|c|c|c|c|c|c|c|c|c|c|c|}
\hline \multirow[b]{2}{*}{ Date } & \multicolumn{11}{|c|}{ Cow No. } \\
\hline & $33^{*}$ & 26 & 256 & $16^{*}$ & 193 & 227 & 234 & 4 & 223 & 803 & 240 \\
\hline 21 & 4.58 & 3.13 & 3.91 & 2.11 & 2.82 & 2.75 & 4.65 & 2.84 & 4.08 & 3.77 & 3.38 \\
\hline 22 & 5.17 & 1.99 & 3.42 & 2.41 & 3.83 & 3.45 & 4.93 & 2.44 & 1.36 & 1.92 & 3.94 \\
\hline 23 & 4.66 & 2.98 & 1.69 & 2.99 & 3.83 & 3.71 & 3.21 & 3.36 & 2.39 & 3.72 & 3.11 \\
\hline 24 & 3.98 & 2.07 & 3.73 & 2.27 & 3.81 & 4.44 & 2.16 & 3.15 & 3.50 & 3.02 & 3.63 \\
\hline 25 & 4.37 & 2.39 & 3.86 & 2.06 & 3.42 & 3.63 & 2.61 & 3.11 & 4.86 & 3.09 & 3.94 \\
\hline 26 & 4.04 & 2.83 & 3.76 & 2.26 & 2.43 & 3.50 & 4.49 & 2.88 & 3.84 & 2.96 & 3.85 \\
\hline 27 & 4.15 & 3.21 & 2.04 & 2.12 & 4.21 & 3.53 & 3.78 & 3.33 & 3.83 & 3.44 & 3.67 \\
\hline 28 & 3.84 & 2.39 & 2.71 & 2.63 & 3.86 & 3.82 & 4.18 & 3.37 & 4.76 & 3.94 & 3.54 \\
\hline 29 & 3.94 & 3.96 & 2.58 & 2.80 & 1.80 & 3.22 & 3.87 & 3.68 & 1.87 & 1.49 & 3.20 \\
\hline Mean & 4.30 & 2.77 & 3.08 & 2.41 & 3.33 & 3.56 & 3.76 & 3.13 & 3.39 & 3.04 & 3.58 \\
\hline
\end{tabular}

*Milk fat content in No. 16 cow was $2.41 \%$ which was the lowest in all the 11 cows, milk fat content in No. 33 cow was $4.30 \%$ which was the highest in all the 11 cows, $p=0.000$

Table 2: Milk protein content in 11 Chinese Holstein cows $(\%)$

\begin{tabular}{|c|c|c|c|c|c|c|c|c|c|c|c|}
\hline \multirow[b]{2}{*}{ Date } & \multicolumn{11}{|c|}{ Cow No. } \\
\hline & $33^{*}$ & 26 & 256 & $16^{*}$ & 193 & 227 & 234 & 4 & 223 & 803 & 240 \\
\hline 21 & 3.19 & 2.91 & 2.81 & 2.83 & 2.98 & 2.98 & 2.97 & 2.98 & 3.10 & 2.97 & 3.01 \\
\hline 22 & 3.58 & 2.92 & 2.84 & 2.76 & 2.98 & 3.40 & 2.93 & 3.06 & 3.15 & 3.00 & 3.04 \\
\hline 23 & 3.21 & 2.98 & 2.84 & 2.71 & 2.97 & 3.35 & 3.06 & 3.17 & 3.15 & 2.93 & 3.55 \\
\hline 24 & 3.07 & 2.97 & 2.92 & 2.81 & 3.09 & 3.13 & 3.01 & 3.00 & 3.24 & 3.05 & 3.06 \\
\hline 25 & 2.96 & 2.96 & 3.23 & 2.74 & 2.95 & 3.09 & 3.04 & 2.91 & 3.21 & 3.00 & 3.13 \\
\hline 26 & 5.27 & 3.02 & 2.90 & 2.67 & 2.89 & 3.08 & 2.94 & 3.27 & 3.60 & 2.97 & 3.25 \\
\hline 27 & 5.03 & 2.97 & 2.63 & 2.89 & 2.90 & 3.12 & 3.10 & 3.71 & 3.20 & 2.90 & 3.17 \\
\hline 28 & 4.58 & 2.82 & 2.96 & 2.83 & 2.93 & 3.22 & 3.11 & 2.58 & 3.15 & 3.05 & 3.09 \\
\hline 29 & 4.30 & 3.03 & 2.96 & 2.92 & 3.10 & 3.22 & 2.81 & 3.32 & 3.32 & 2.93 & 3.12 \\
\hline Mean & 3.91 & 2.95 & 2.90 & 2.80 & 2.98 & 3.18 & 3.00 & 3.11 & 3.24 & 2.98 & 3.16 \\
\hline
\end{tabular}

*Milk protein content in No. 16 cow was $2.80 \%$ which was the lowest in all the 11 cows, milk protein content in No. 33 cow was $3.91 \%$ which was the highest in all the 11 cows, $p=0.000$ 
media was replaced with fresh media every $48 \mathrm{~h}$ until culture dish was full of cells. Cells were detached with $0.25 \%$ trypsin- $0.02 \%$ EDTA (GIBCO) and transferred to new culture dishes which were used to remove fibroblasts. Subsequently, the pure mammary epithelial cells were isolated after 3-5 passages.

Characteristic of mammary epithelial cells by growth curves draw: About $6 \times 10^{3}$ cells/well were seeded in 96 well flat-bottom culture plates (Falcon) containing basal media. The number of cells were counted by counting plate under an inverted microscope after every $24 \mathrm{~h}$ until 9 days. Before counting the cells, researchers digested all the cells in a well and added $200 \mu \mathrm{L}$ PBS. Then, researchers dropped $10 \mu \mathrm{L}$ the mixed PBS solution in the counting plate. Within 9 days, the basal media were replaced with fresh media every $48 \mathrm{~h}$ without digestion. The growth curves were drew on the basis of the earlier data.

Cells nucleus staining analysis by Giemsa stain solution: The purified cells which were cultured in cover glass slides (Tiangen, Beijing, China) were examined via staining analysis of cells nucleus. The cells were rinsed with PBS solution three times and were suspended with formalin (Tiangen) solution. The slides were then stained with Giemsa stain solution (Tiangen) $1 \mathrm{~mL}$ for $15 \mathrm{~min}$, washed with distilled water and dried at room temperature. Cells nucleus were visualized and detected with microscope.

RT-PCR for $\alpha$-s1 casein and $\kappa$-casein expression in mammary epithelial cells: Total RNA from mammary epithelial cells were isolated with RNA extraction kit (Tiangen). The expression of $\alpha$-s 1 casein and $\kappa$-casein were examined by RT-PCR. The integrity and concentration of the RNA were verified by analyzing $5 \mu \mathrm{L}$ of each sample on a $1 \%$ agarose gel and ultraviolet spectrophotometer (Alpha). Reverse transcription system: $5 \times$ RNA RT buffer, $4 \mu \mathrm{L}$; dNTP mixture (10 mM), $3 \mu \mathrm{L}$; Oligo-dT, $1 \mu \mathrm{L}$; AMV Reversev transcriptase $\left(5 \mathrm{U} \mu \mathrm{L}^{-1}\right), 1 \mu \mathrm{L}$; RNase inhibitor $\left(40 \mathrm{U} \mu \mathrm{L}^{-1}\right), 0.5 \mu \mathrm{L}$; Total RNA, $6 \mu \mathrm{L}$; RNase free $\mathrm{H}_{2} \mathrm{O}, 4.5 \mu \mathrm{L}$. Reverse transcription procedure: $42^{\circ} \mathrm{C}, 50 \mathrm{~min} ; 95^{\circ} \mathrm{C}, 10 \mathrm{~min}, 0^{\circ} \mathrm{C}$ and $5 \mathrm{~min}$. Primers of $\alpha$-s1 casein and $\kappa$ - casein were designed with primer 5.0 (Table 2) and synthesized by Shanghai Sangen Biological Engineering Technology Corporation.

Examination of Cytokeratin 18 by immunofluorescence in mammary epithelial cell: Cytokeratin 18 was examined by seeding $1 \times 10^{5}$ cells/well in 6 well flat-bottom culture plates (Falcon). CK18 expression was examined after $24 \mathrm{~h}$. First, the cells were washed by PBS solution and fixed
15 min with ice-cold acetone-formaldehyde (Tiangen) (8:2). Cells were then washed $5 \mathrm{~min}$ with PBST for three times. Nonspecific reactivity was blocked with goat serum (Takara, Dalian, China) for $1 \mathrm{~h}$ at room temperature and washed $5 \mathrm{~min}$ with PBST for 3 times. First antisera (BOSTER, Beijing, China) anti-cytokeratin 18 was diluted $1 / 100$ in PBS solution and incubated for $1 \mathrm{~h}$ at room temperature. The cells were washed $3 \times 5$ min with PBST. Second, antibody FITC-conjugated monoclonal antirabbit IgG (BOSTER) was diluted $1 / 100$ in PBS and incubated in the dark for $30 \mathrm{~min}$. Cells were washed with PBS for three times and visualized with a fluorescence microscope.

Comparison of the TG content in MEC-HH and MEC-LL for the difference of the two types of cell lines: To examine cell lines whether kept the characters of high fat and low fat cows. A TG-kit (BHKT, Beijing, China) was used for detecting TG content in both MEC-HH and MEC-LL. The $1 \times 10^{5}$ cells/well were seeded in a 6 well flat-bottom culture plates, DMEM/F12 without serum were added into the wells. After $48 \mathrm{~h}$, researchers collected the cells then adjusted the concentration to ensure the cells number was at equal. The cells were broked by a transonic machine. The other operation followed the manufacturer's protocols. To decrease the influence of same culture condition, the cells in passage 2 and 5 were chose.

Statistical analysis: All paired comparisons were subject to a two tailed Student $\mathrm{t}$-test with $\mathrm{p}<0.05$ considered statistically significant.

\section{RESULTS AND DISCUSSION}

Morphology of MEC-HH and MEC-LL: For the mammary tissue from the low fat low protein cow, within 6 days but for the mammary tissue from the high fat high protein cow, within 10 days, most cells began to grow outward from the attached organoid or cell clumps. Elongated cells and large polygonal cells spread and grew from the organoid and formed sheets of cells. The cells formed preconfluent monolayers by day 10 for MEC-LL and day 14 for MEC$\mathrm{HH}$. At this time, two kinds of cells located in the plates. After about 2 weeks, primary epithelial cells became the dominant cell types. Generally, it took more time to digest epithelial cells than fibroblasts with trypsin and EDTA solution. Subsequently, the pure mammary epithelial cells were isolated after 3-5 passages (Fig. 1). We can see, most of the isolated cells that extended from the tissue had a cobble stone like shape, clear boundary and were connected tightly. 


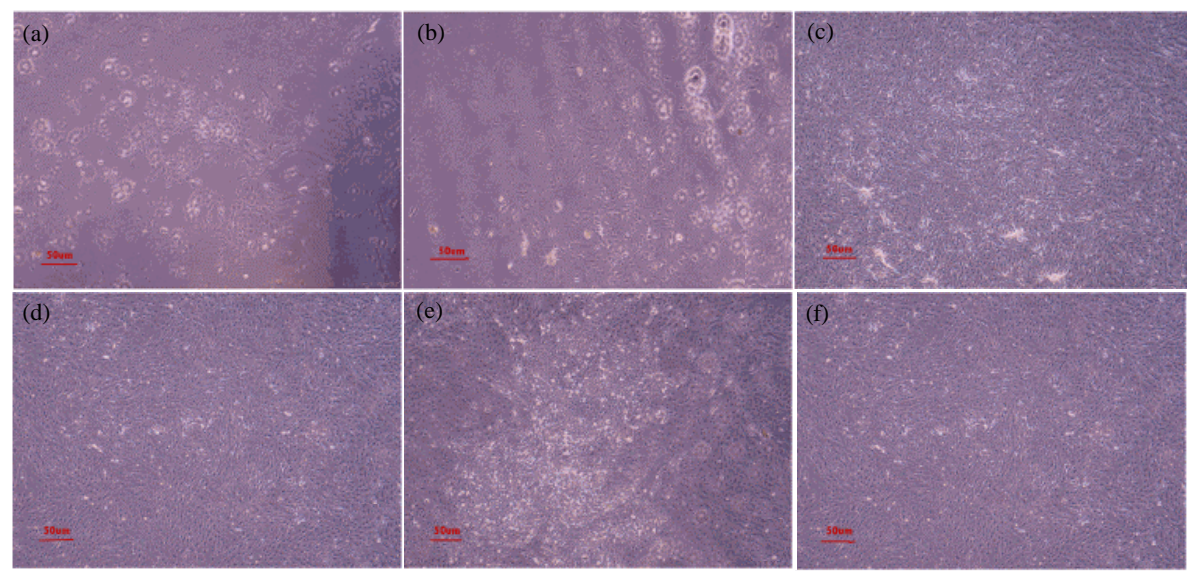

Fig. 1: Purified Chinese Holstein cow high fat high protein mammary epithelial cells and low fat low protein mammary epithelial cells. Tissue culture method was employed to culture cells; a, b) synbiosis of fibroblast and epithelial cells separated from cows with high fat high protein milk and low fat low protein milk, respectively; c, d) purified epithelial cells grew from mammary tissue with high fat high protein and low fat low protein, respectively and e, f) epithelial cells separated from cows with high fat high protein milk and low fat low protein milk showed honeycombing

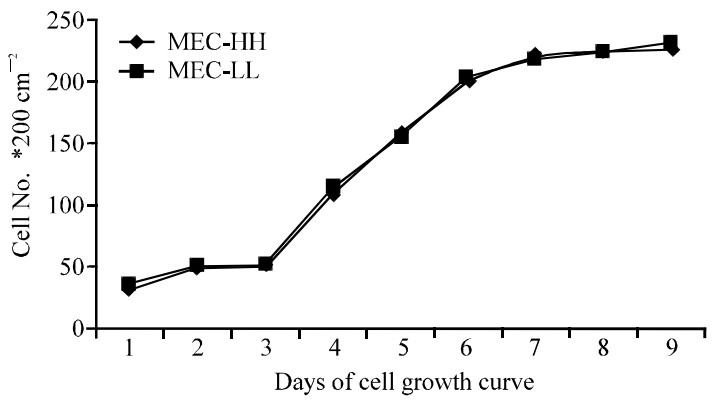

Fig. 2: MEC-HH and MEC-LL growth curve. The growth curve conformed to the rule of $\mathrm{S}$ sigmoid curve suggested the cells maintained a favorable growth performance

\section{The result of growth curve of the two types of mammary} epithelial cells: During the 1 st 3 days of the latent phase, the growth rate was slow but during the following 3 days of growth there was an increase in cell number followed by a steady phase for the last several days of culture (Fig. 2). Thus, the growth curve conformed to the rule of $\mathrm{S}$ sigmoid curve for proliferating cells with a lag-phase, exponential phase and steady phase. This suggested that the isolated bovine mammary epithelial cells, no matter MEC-HH or MEC-LL, all maintained a favorable growth performance.

The result of staining analysis of cells nucleus: The result from Giemsa staining showed that the cells displayed polygon, the cells nucleus are round or elliptic.
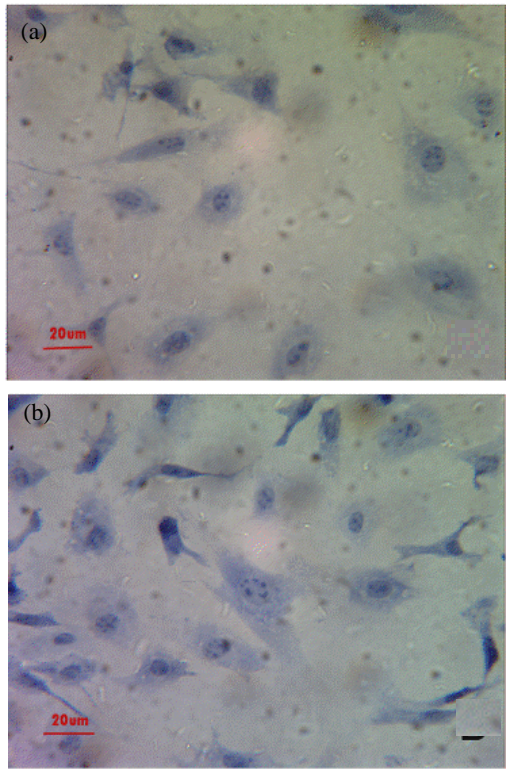

Fig. 3: The results of Giemsa staining in mammary epithelial cell lines. There were 2-4 nucleoli per cell suggest that cells we isolated were in a active state. a) The result of high fat high protein epithelial cells in Giemsa staining. b) The result of low fat low protein epithelial cells in Giemsa staining

There are 2-4 nucleoli per cell (Fig. 3). The result indicated that the cells we isolated were in an active state and could be used for the followed studies. 


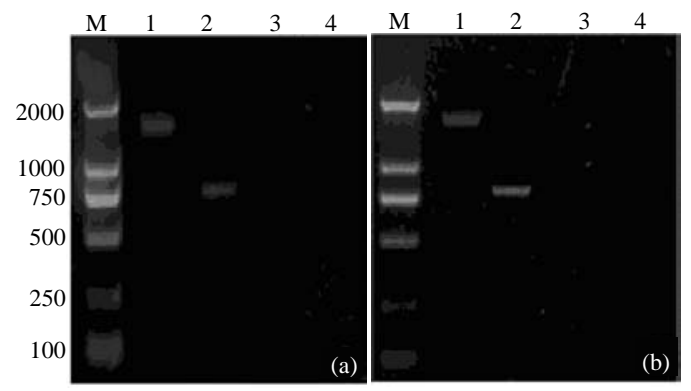

Fig. 4: Chinese Holstein cow mammary epithelial cells $\alpha-$ $\mathrm{s} 1$ casein and $\kappa$-casein protein identification results. RT-PCR was employed for detecting $\alpha$-s 1 casein and $\mathrm{k}$-casein in MEC-HH and MEC-LL. M for D2000 standard for the molecular weight Marker, 1 lane for the $\alpha$-s1 casein of MEC-HH, 5 lanes for the $\mathrm{K}$-casein of MEC-HH, lane 3, 7 for the negative control fibroblasts for $\alpha$-s1 casein, lane 2 for the $\alpha$-s1 casein of MEC-LL, lane 6 for the $\kappa$-casein of MEC-LL, lane 4, 8 for the negative control fibroblasts for $k$-casein

The RT-PCR result of $\alpha$-s1 casein and $\kappa$-casein expression: Reverse transcription-PCR amplification of mRNA from bovine mammary gland cultures demonstrated the cells we isolated expressed $\alpha$-s1 casein and $\kappa$-casein (Fig. 4). The $\alpha$-s 1 casein is $1736 \mathrm{bp}$ and $\mathrm{K}$-casein is $780 \mathrm{bp}$. The RT-PCR result indicated that the mammary epithelial cells we isolated had normal secretion function.

Cytoskeleton 18 expression in mammary epithelial cell lines: Although, the cell lines we established appeared to have epithelial cell morphology, we further investigated homogeneity at the sixth passage and also at the resuscitated cells by examining the protein expression of cytoskeleton. Cytoskeleton 18, a specific protein for epithelial was examined by immunofluorescence. Most isolated epithelial cells were positively-stained and the fibroblast cells were negatively-stained as a control (Fig. 5). The results indicated that the cells we isolated were pure epithelial cells without other type of cells. The positive staining for cytokeratin-18 was a powerful result to prove the specific epithelium character of mammary epithelial cells.

TG content in MEC-HH and MEC-LL in passage 2 and 5: We detected TG content in MEC-HH and MEC-LL in passage 2 and 5. The statistical significance of differences in mean values was assessed using SPSS 13.0 Statistic Software. In passage $2, \mathrm{p}=0.009<0.05$ was considered statistically significant but in passage $5, \mathrm{p}=0.844>0.05$

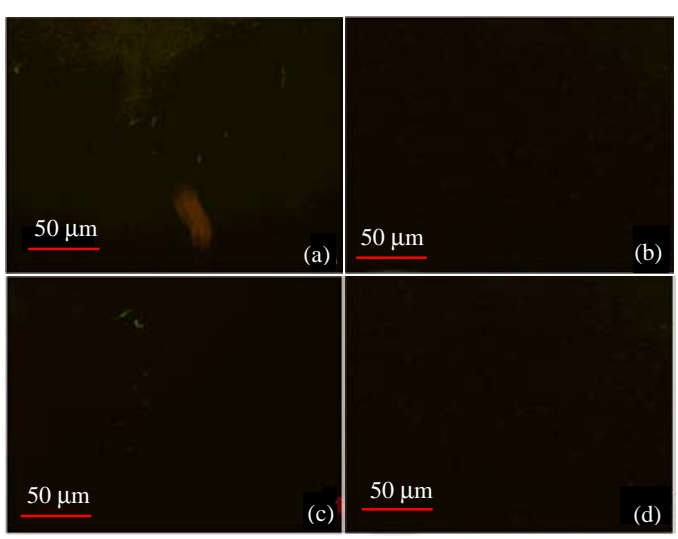

Fig. 5: Keratin 18 immunofluorescence results Cytoskeleton 18, a specific protein for epithelial, was examined by immunofluorescence; a) isolation and culture of high fat high protein mammary epithelial cells; b) isolation and culture of low fat low protein mammary epithelial cells and c, d) negative control embryo fibroblasts

Table 3: The primer design and the length of PCR amplification fragments

\begin{tabular}{llc}
\hline Gene & Sequence & $\begin{array}{c}\text { Length of } \\
\text { product (bp) }\end{array}$ \\
\hline$\alpha$-sl casein F: 5'-GCTCCTTCAGAAGAGTCAAGTG -3' & 1736 \\
& R: 5'-GTTACTGTGTGTCCTGTTTTAACC -3' & \\
\multirow{2}{*}{ k-casein } & F: 5'-CGCTGTGAGAAAGATGAA AGATTC -3' & 780 \\
& R: 5'-AGATTCAAGGAGTATACCAATTGTTG-3' & \\
\hline
\end{tabular}

was considered not significant. Thus, the results indicated that, TG content was different between MEC$\mathrm{HH}$ and MEC-LL in passage 2 but in passage $5 \mathrm{TG}$ content in the two types of cells were nearly equal (Table 3 and 4).

To decrease the influence of milk quality in different raised conditions, we chose 11 lactating Chinese Holstein cows grew in the same circumstance. To ensure the data is accurate, we persistently monitored milk quality of the 11 cows for 9 days with milk composition analysis machine and we calculated the average milk fat content and milk protein content then two cows whose milk fat and milk protein were highest and lowest was chose and butchered. The cells isolated from the two cows kept their characteristic about milk fat and protein within 2 passages but in the 5th passage, the two types of cells had almost same TG contents. We considered the possible reason was that cells absorbed nutrition from the same medium in vitro and after cultured a long time, the two types of cells tended to assimilation.

The previous studies suggested that DMEM and DMEM/F12 were more suitable than F12 and RPMI1640 (Shamay and Gertler 1986). Evaluation of the cell population doubling time suggested that 10\% FBS was 
Table 4: TG contents in MEC-HH and MEC-LL of passage 2 and passage 5

\begin{tabular}{lcccccc}
\hline Samples & MEC-HH1 & MEC-HH2 & MEC-HH3 & MEC-LL1 & MEC-LL2 & MEC-LL3 \\
\hline TG contents in passage 2* $\left(\mathrm{mmol} \mathrm{L}^{-1}\right)$ & 0.8645 & 0.8373 & 0.8985 & 0.6217 & 0.7421 & 0.6882 \\
TG contents in passage 5 $\left(\mathrm{mmol} \mathrm{L}^{-1}\right)$ & 0.5209 & 0.4943 & 0.5022 & 0.4878 & 0.4799 \\
"In passage 2, p was 0.009 $<0.05$, in passage 5, p was 0.844>0.05; & MEC-HH: Mammary Epithelial Cell from High fat High protein cow, MEC-LL: Mammary \\
Epithelial Cell from low fat low protein cow &
\end{tabular}

the optimal concentration in growth media (Park et al., 1979; Akers et al., 1986). Some results suggested that the concentration of Fetal Bovine Serum (FBS) in media had a strong effect on the proliferation of bovine mammary epithelial cells (Mackenzie et al., 1982). When compared with $0 \%$ FBS treatment, bovine mammary epithelial cells grown in 5-10\% serum underwent a 3-4 fold increase in cell number during the 12 days of culture (Mackenzie et al., 1982). The results suggested that DMEM/F12 were suitable for the growth of mammary epithelial cells and a frozen solution with $90 \% \mathrm{FBS}$ and $10 \%$ DMSO was optimal for cell preservation. Though at the first, the cells isolated from high fat high protein cow grew slower than cells isolated from low fat low protein cow (the possible reason was that the cells growth rate was influenced by lipometabolism), the grew rate of the two types of cells tend to be equal after 2 passages and there is no significant different between the two types of cell lines in morphology, growth characteristics, cytogenetic and secretory characteristics.

The growth curves showed that the mammary epithelial cells, no matter MEC-HH or MEC-LL maintained a favorable growth performance. During the 1st 3 days, the cells grew slow and stayed in a latent phase. But during the following 3 days of growth there was an increase in cell number, during the last several day, the growth rate was steady. Thus, the growth curve conformed to the rule of S sigmoid curve for proliferating cells (Barcellos-Hoff et al., 1989). Therefore, the two types of mammary epithelial cells we isolated had a normal proliferate capability and this response was similar to the results of Cifrian (Baumrucker et al., 1988).

Cytokeratin 18 is one of the most common members of the intermediate filament gene family and generally exists together with its filament partner keratin 8. It is expressed in single layer epithelial tissues of the body and is specific for epithelial cells. Immunocytochemical staining of goat mammary tissue showed that cytokeratin 18 was found in both epithelial and myoepithelial cells of goat mammary gland (Hurley et al., 1989). Bovine myoepithelial cells were negative to anti-cytokeratin 18 monoclonal antibody. In the study, the obtained bovine mammary epithelial cells which had stained positive for anti-cytokeratin 18 , exhibited the same phenomenon as reported previously. The positive staining for cytokeratin18 was a powerful result to prove the specific epithelium character of MECs.
Epithelial differentiation is also characterized by expression of milk proteins such as $\alpha$-slcasein and $\kappa$-casein, the production of milk fat rich in triglycerides, sources of energy and essential fatty acids (Gertler et al., 1982). Casein secretion is the hallmark of the bovine mammary epithelial cells (Beswick and Kennelly, 1998). The results from the study showed that the cells isolated had normal secretion function.

\section{CONCLUSION}

The study demonstrated that the establishment of these two bovine mammary epithelial cell lines from Chinese Holstein cattle exhibited normal function. And the isolated mammary epithelial cells have been used for investigation of gene function about milk fat and protein and lipometabolism mechanism study.

\section{ACKNOWLEDGEMENTS}

This research was supported by the National $\mathrm{R}$. and D. Project of Transgenic Organisms of Ministry of Science and Technology of China (2008ZX08007-001, 2009ZX08009-156B and 2009ZX08007-005B) and National Natural Science Foundation of China (No. 31000991). Researchers thank the anonymous reviewers for their time and energy in reviewing this study. Chunyan Lu and Runjun Yang contributed equally to this research.

\section{REFERENCES}

Akers, R.M., T.B. McFadden, W.E. Beal, A.J. Guidry and H.M. Farrell, 1986. Radioimmunoassay for measurement of bovine $\alpha$-lactalbumin in serum, milk and tissue culture media. J. Dairy Res., 53: 419-429.

Barcellos-Hoff, M.H., J. Aggeler, T.G. Ram and M.J. Bissell, 1989. Functional differentiation and alveolar morphogenesis of primary mammary cultures on reconstituted basement membrane. Development, 105: 223-235.

Baumrucker, C.R., K.P. Deemer, R. Walsh, T.L. Riss and R.M. Akers, 1988. Primary culture of bovine mammary acini on a collagen matrix. Tissue Cell, 20: 541-554.

Beswick, N.S. and J.J. Kennelly, 1998. The influence of bovine growth hormone and growth hormone releasing factor on acetyl-CoA carboxylase and fatty acid synthase in primiparous Holstein cows. Comp. Biochem. Physiol. Part C: Pharmacol. Toxicol. Endocrinol., 120: 241-249. 
Ceriani, R.L., J. Taylor-Papadimitriou, J.A. Peterson and P. Brown, 1979. Characterization of cells cultured from early lactation milks. In vitro, 15: 356-362.

Cifrian, E., A.J. Guidry, C.N. O'Brien, J.E. Jr. Keys and W.W. Marquardt, 1994. Bovine mammary teat and ductal epithelial cell cultures. Am. J. Vet. Res., 55: 239-246.

Ethier, S.P., 1986. Serum-free culture conditions for the growth of normal rat mammary epithelial cells in primary culture. In vitro Cell. Dev. Biol., 22: 485-490.

German, T. and I. Barash, 2002. Characterization of an epithelial cell line from bovine mammary gland. In vitro Cell. Dev. Biol. Anim., 38: 282-292.

Gertler, A., A. Weil and N. Cohen, 1982. Hormonal control of casein synthesis in organ culture of the bovine lactating mammary gland. J. Dairy Res., 49: 387-398.

Gorgulu, O., 2011. Path analysis for milk yield characteristics in jersey dairy cows. Asian J. Anim. Vet. Adv., 6: 182-188.

Han, B., H.L. Zhang, L. Zeng, B. Yang, R. Abula, X.L. Xu and Y. Chen, 2011. The Polymorphisms of $\beta_{2}$ Adrenergic Receptor Gene on two Cattle Breeds in China Asian J. Anim. Vet. Adv., 6: 715-722.

Hu, H., J. Wang, D. Bu, H. Wei, L. Zhou, F. Li and J.J. Loor, 2009. In vitro culture and characterization of a mammary epithelial cell line from Chinese Holstein dairy cow. PLoS One, 4: e7636-e7636.

Huang, J., L. Liu, H. Wang, C. Zhang and Z. Ju et al., 2011. Variants and gene expression of the TLR2 gene and susceptibility to mastitis in cattle. Asian J. Anim. Vet. Adv., 6: 51-61.

Hurley, D., S.I. Hwang and V. Rocha, 1989. Casein accumulation in distended rough endoplasmic reticulum of collagen gel-cultivated mouse mammary epithelia. J. Cell. Physiol., 141: 135-141.

Huynh, H.T., G. Robitaille and J.D. Turner, 1991. Establishment of bovine mammary epithelial cells (MAC-T): An in vitro model for bovine lactation. Exp. Cell Res., 197: 191-199.

Jack, J.W. and I.H. Mather, 1990. Cloning and analysis of cDNA encoding bovine butyrophilin, an apical glycoprotein expressed in mammary tissue and secreted in association with the milk-fat globule membrane during lactation. J. Biol. Chem., 265: 14481-14486.
Mackenzie, D.D.S., I.A. Forsyth, B.E. Brooker and A. Turvey, 1982. Culture of bovine mammary epithelial cells on collagen gels. Tissue Cell, 14: 231-241.

Martignani, E., P. Eirew, P. Accornero, C.J. Eaves and M. Baratta, 2010. Human milk protein production in xenografts of genetically engineered bovine mammary epithelial stem cells. PloS One, 5: e13372-e13372.

Pantschenko, A.G., J. Woodcock-Mitchell, S.L. Bushmich and T.J. Yang, 2000a. Establishment and characterization of a Caprine Mammary Epithelial Cell line (CMEC). In vitro Cell. Dev. Biol. Anim., 36: 26-37.

Pantschenko, A.G., M.R. Barber, J. Woodcock-Mitchell, S.L. Bushmich and T.J. Yang, 2000b. Establishment and characterization of a caprine mammary myoepithelial cell line (CMMyoEC). In vitro Cell. Dev. Biol.-Anim., 36: 351-356.

Park, C.S., J.J. Smith, M. Sasaki, W.N. Eigel and T.W. Keenan, 1979. Isolation of functionally active acini from bovine mammary gland. J. Dairy Sci., 62: $537-545$.

Rapp, F. and J. L. Melnick, 1964. Applications of tissue culture methods in the virus laboratory. Prog. Med. Virol., 6: 268-317.

Rose, M.T., H. Aso, S. Yonekura, T. Komatsu, A. Hagino, $\mathrm{K}$. Ozutsumi and $\mathrm{Y}$. Obara, 2002. In vitro differentiation of a cloned bovine mammary epithelial cell. J. Dairy Res., 69: 345-355.

Schmid, E., W.W. Franke, C. Grund, D.L. Schiller, H. Kolb and N. Paweletz, 1983. An epithelial cell line with elongated myoid morphology derived from bovine mammary gland: Expression of cytokeratins and desmosomal plaque proteins in unusual arrays. Exp. Cell Res., 146: 309-328.

Shamay, A. and A. Gertler, 1986. A model for in vitro proliferation of undifferentiated bovine mammary epithelial cells. Cell. Biol. Int. Rep., 10: 923-929.

Szyda, J. and J. Komisarek, 2007. Statistical modeling of candidate gene effects on milk production traits in dairy cattle. J. Dairy Sci., 90: 2971-2979.

Zakizadeh, S., A. Nejati-Javaremi, M. Reissmann, G. Rahimi and A. Jahan Bakhshi, 2007. Analysis of selection effect based on kappa casein gene on milk yield production of Iranian Sarabi cattle breed using stochastic simulation. Pak. J. Biol. Sci., 10: 941-945.

Zavizion, B., M. van Duffelen, W. Schaeffer and I. Politis, 1996. Establishment and characterization of a bovine mammary myoepithelial cell line. In vitro Cell. Dev. Biol. Anim., 32: 149-158. 